\title{
Traffic Survey Analysis: Implications for Road Transport Planning In Nigeria
}

\author{
Umar Obafemi Salisu $^{1 *}$ and Olukayode O. Oyesiku ${ }^{2}$
}

${ }^{1}$ Olabisi Onabanjo University, Department of Urban and Regional Planning, Ago-Iwoye, Ogun State, Nigeria; Email: obafemiumar@gmail.com

${ }^{2}$ Olabisi Onabanjo University, Department of Geography, Ago-Iwoye, Ogun State, Nigeria; Email: oyesikuoo@gmail.com

\section{*Corresponding Author: Umar Obafemi Salisu}

Received: 1 June 2020; Revised: 27 Jul 2020; Accepted: 3 August 2020; Published: 30 November 2020

Abstract: Efficient traffic survey analysis is a catalyst for achieving an efficient and advanced transport planning and sustainable urban development. Unfortunately, the obvious decline in the traffic survey on Nigerian urban roads has left the road transport system to be handicap of traffic data, quality service deliveries and characterized by traffic-related quagmires with devastating socio-economic consequences including congestion, crime and crash incidences. This paper examined traffic survey analysis on major highways in Ogun State, Nigeria using manual traffic count method for estimation of traffic volume and flow pattern. The traffic data gathered were presented and analyzed using descriptive and inferential (ANOVA and Student ' $t$ ' test) techniques to determine variations in vehicular traffic volume and flow situation (inbound and outbound). Findings revealed that Car/SUV is the most dominant traffic relative to others. Meanwhile, ANOVA results show significant variation in traffic volume on the selected highways ( $\mathrm{p}$. value $<0.05$ ), while, the Student ${ }^{\mathrm{t}} \mathrm{t}$ ' test shows no significant difference between traffic inbound and outbound. Findings also revealed that the physical condition of the highways is relatively poor. Based on these findings, the study recommended improvement measures and strategies to curtail traffic-related issues towards achieving efficient, safe, and quality road transport planning in Nigeria.

Keywords: Highway, traffic volume, traffic flow, manual count

\section{Introduction}

Transport no doubt plays a pivotal role in the overall development and continuous existence of every society. It facilitates the movement and interaction among spatial units and influences the overall 
developmental strategies towards achieving socio-economic, political and cultural aspirations [1]. It is worth knowing that the available transport system, particularly its infrastructure and network, is an important yardstick for measuring economic development of any nation and serves as a propelling wheel for which socio-economic activities move [2]. Road transport, most especially in developing nations, enjoys significant advantages over other modes of transport due to its physical characteristics of the door to door services, short distance travel, and vehicle operational flexibility among others [3]. Major percentages of regional and national traffic movements are achieved through this most popular land-based transport mode, with its increasing demands reflected on both intra-and-inter city traffic flows. Hence, the importance of understanding the road traffic situation, required infrastructural facilities support and investments cannot be ignored. Nevertheless, efficient functioning of road transport infrastructure and network capacity requires continuous and systematic planning and improvement strategies including the maintenance and forecasting of the future traffic pattern and travel behaviour on the existing road network, all of which are possible upon an adequate collection of traffic data through appropriate traffic volume and flow survey method of transport planning [4-6].

Road traffic survey is a vehicular or pedestrian traffic count which observes passings along spatially separated points, routes, roads, paths or intersections at a specific time interval through either manual observation or automated observation [6-8]. Ref. [9] observed that traffic survey helps determine and accurately reflect the real-world traffic situation including the up-to-date number of passing vehicles or pedestrian, movement flow periods, pattern and classification at a given location mainly to road transport planning. However, the demand for traffic survey facilitates the assessment of present and future traffic demands for better development of transport infrastructural planning and traffic monitoring towards ensuring all-time data availability needed to undertake necessary transport project design, construction, and maintenance and for achieving efficient flow, a better quality of services and functional capacity measures without compromising the safety of both people and freight on transit $[4,10]$. Ref. [11] noted that traffic survey through the quality volume and flow analysis provides the basic data that can allow both public policy decision and market-based decision in the provision of transport infrastructure and services since both forces are becoming more important in determining not only the quantity of demand and supply but also achieving the overall quality transport services.

Unfortunately, despite the importance of the traffic survey in planning transport systems, the Nigeria transport sector has been declining in the planning for the changing dynamics in its transport system for a few decades. This shortfall has left the system to be a handicap of quality service deliveries, particularly the inability of the national and regional road network capacity to meet and 
accommodate the increasing level of traffic demands and automobile use, which is not unconnected to poor planning, weak policy, unprecedented population increase and overreliance on the on-road mode in conjunction with the systematic withdrawal of the government in the provision of the conventional public transport system. Across Nigeria, the larger percentage of the road transport networks suffer from obvious neglect, limited capacity expansion, poor maintenance culture, lack of facilities and furniture for efficient flow operation, and traffic bottlenecks including congestion, crime and crash incidents. However, these multifarious challenges have socio-economic and environmental impacts on the national economy of Nigeria and other developing countries where the pattern of development is accompanied by the urbanization surge leading to irrational land use activities, emergency of urban land sprawl with the consequence of unpredictable travel time and high cost of vehicle use [1]. Accordingly, Ref. [11] observed that traffic levels across the world have doubled while the expansion and maintenance of transport infrastructure have not met the expected levels of an increased demand in the road network capacity, particularly highways, resulting in the inevitable increase in poor service quality and congestion. Hence, undertaken traffic survey through volume and flow analysis will provide a prerequisite for an effective evaluation and planning of road transport system as well as curtailing the unwanted and existing traffic-related quagmires most especially congestion, unpredictable travel time, crime and crash incidences along Nigerian road corridors.

Based on the foregoing, the study examined traffic survey analysis: implications for road transport planning in Nigeria. In achieving this aim, its specific objectives were to examine the traffic volume and classification on three major highways in Ogun State, Nigeria, assess the variation in the inbound and outbound traffic flow towards determining the traffic situation on the selected highways as well as determining the quality of the physical condition of selected highways towards proffering better measures for sustaining the road transport system in the State and the country at large.

\section{Concept of Traffic Volume and Classification}

The focus of traffic volume survey is to collect data on the number and types of passing vehicles in a specified point on a route or link or at a junction at a specific period [12]. This involves the determination of vehicle or pedestrian numbers, vehicle types, vehicle speeds, vehicle weights, as well as more substantial information such as trip length and trip purpose and trip frequency [4]. At times, the occupancy of vehicles may also be recorded to provide data on the volume of people using the road space. However, traffic volume is expressed as a rate of flow, usually, either as vehicles per hour (veh/h) and in particular, the hour involves counting on the road for a day or vehicles per day (veh/day) and for twelve months of a year are often converted into the Average Daily Traffic (ADT) and Annual 
Average Daily Traffic (AADT) [4,12,13]. Manual counts are particularly useful for vehicle classification, checking automatic counter accuracy, and surveying vehicle occupancy. Automatic traffic counts, using traffic counter equipment, are normally used only on links, and are particularly suitable for long-term data collection, and analyzing seasonal, daily, and hourly variations. In most complex studies, a combination of automatic and manual counts is needed $[4,5,12]$. In other words, traffic counts during a Monday morning rush hour and a Friday evening rush hour may show exceptionally high volumes and are not normally used in the traffic analysis; therefore, counts are usually encouraged on a Tuesday, Wednesday, or Thursday for true traffic situation.

\subsection{Manual Traffic Counts}

The manual counting requires a surveyor(s) standing by the roadside, counting and classifying vehicles as they pass and by dividing the survey into fixed periods [7,9]. Route counts should be located on straight sections of road for good visibility and with duration ranges from a few minutes to hours, and several days, depending on the purpose. Most applications of manual counts require small samples of data at any location and are mostly used when the effort and expense for automated equipment are not justified or available [7,14]. However, manual counts are recorded using any of these methods: tally sheets, mechanical counting boards, or electronic counting boards. Tally Sheets which involves recording the data onto tally sheets is the simplest means of conducting manual counts. The data can be recorded with a tick mark on a pre-prepared field form using a watch or stopwatch to measure the desired count interval [15]. Mechanical Counting Boards (MCB) consists of counters mounted on a board that records each direction of travel. Common counts include pedestrian, bicycle, vehicle classifications, for volume counts are usually facilitated using mechanical count boards. MCB uses typical counters of push-button devices with three to five registers to represents different stratification of the vehicle type or pedestrian being counted using a stopwatch [4,15]. However, the limited number of buttons on the counter restricts the number of vehicle classifications that can be counted on a given board. While Electronic Counting Boards (ECB) are battery-operated, hand-held devices used in collecting traffic process data that are similar in the function to mechanical counting boards; however, there are some important differences. ECB is lighter, a more compact, easier to handle device that has an internal clock that automatically separates the data by time interval and with distinct functions which include automatic data manipulation and downloading of data summary to a computer, which saves time. In other words, errors with manual counts usually arise from any of these error sources: failure to define vehicle classification unambiguously, which can lead to undetected errors; failure to 
observe periods accurately; and human error, having to count vehicles at a faster rate than they are capable $[7,15]$.

\subsection{Automatic Count Method}

The automatic count method provides an automated means for gathering large amounts of traffic data, usually taken in 1-hour intervals for every 24 hours and may be extended for a week, month, or year using any of these methods: portable counters, permanent counters, and videotape [4,7]. Portable Counters is an automatic form through similar to manual observation, uses portable devices such as Pneumatic road tubes which serve the same purpose as manual counts but with a piece of automatic counting equipment [15]. Permanent Counters is an automated counter used when long-term counts are to be conducted, usually for more than 24 hours counts -days, months, a year or more [7]. Permanent counters are not a cost-effective option in most situations but the data collected through it are highly reliable and can be used to monitor and evaluate traffic volumes and trends over a long period [15]. Videotape makes use of videotaping devices such as videotape recorder and camcorder in recording traffic volume data at a collection site [4]. A digital clock in the video image can prove useful in noting time intervals. Similar to permanent counters, videotaping is not a cost-effective option either.

\section{Materials and Methods}

Ogun state is located in the Southwestern part of Nigeria and occupies $16,742 \mathrm{~km}^{2}$ representing about 1.82 per cent of the total Nigerian land area. It has a disproportionate growth of population compared with many other states in Nigeria. The Gateway state is densely populated with a population of about 6 million in 2019 [3]. In other words, this survey covers only three prominent highways in Ogun State, Nigeria in 2016 and updated 2019, these are Abeokuta-Lagos Highway (Fig. 1); Sagamu-Benin Highway (Fig.2), and Lagos-Ibadan Highway (Fig. 3). It is pertinent to note that three (3) cordon points were used as screen line points having one per expressway, they include; Wapco LafargeEwekoro (Fig. 1); Coleman Nigerian Wires and Cable Distributor CNWCD (Fig. 2) and NASFAT Praying Ground Mowe-Ibafo (Fig. 3) cordon points, with traffic count carried out for three consecutive days of a week (Tuesday, Thursday and Saturday) within 7 am to $7 \mathrm{pm}$ daily. The justification for picking these three days of the week was to avoid traffic count during Monday and Friday rush hours, which if observed, may show exceptionally high volume and perhaps are not normally used in the analysis; therefore, on the counting took place on Tuesday, Thursday and Saturday. The study also took to cognizance the ways of measuring traffic volume using the manual method of the vehicular count with the help of research assistants and police officers to ensure thorough observation and safety of the 
investigators. In other words, the researchers and their assistants observed traffic volume counting of Bicycle/Motorcycle, Car/SUV, Mini Bus/Van, Trailer, Truck, Tanker, Luxurious Bus, and Tricycle/Auto Rickshaw.

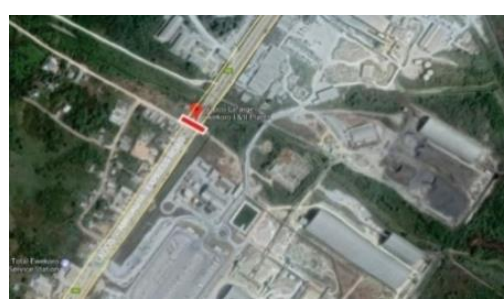

Fig. 1 Abeokuta-Lagos highway (Lafarge Ewekoro C.P.). Source: authors

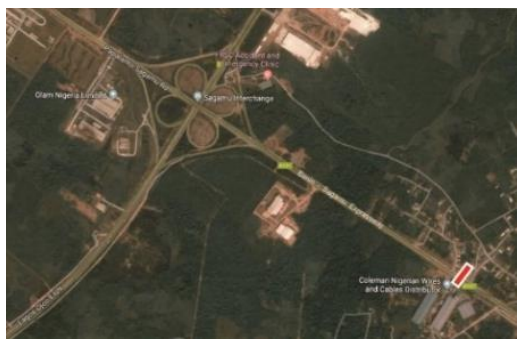

Fig 2 Sagamu-Benin highway (CNWCD C.P.). Source: authors

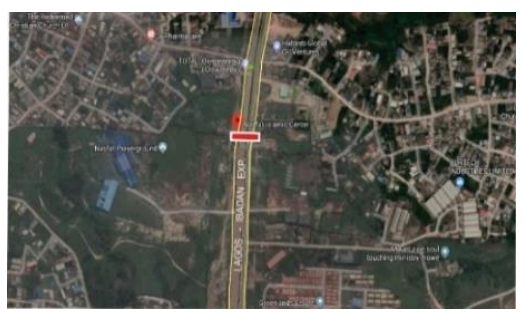

Fig. 3 Lagos-Ibadan expressway (Mowe-Ibafo C.P.). Source: authors

In other words, data analysis were conducted through the use of inferential statistical techniques of Analysis of Variance and Student ' $t$ ' test. ANOVA was used to measure the variation in vehicular traffic for the observed days by routes, while Student ' $t$ ' test measures the statistical difference between Inbound and Outbound traffic flow for the sampled routes. However, these techniques of analysis were employed towards understanding the traffic situation and planning for the sustainability of future traffic demands. 


\section{Findings and Discussion}

\subsection{Traffic Volume and Classification on the Selected Highways}

The results of the traffic volume survey carried out across the three different highways show uniform results of a higher number of Car/SUV type $(108,915)$ relative to other vehicle types. This implies that the use of Car/SUV vehicular type is more predominant on Nigerian roads than others (Table 1). Unfortunately, this observation is not unconnected to the obvious decline and failure of Governments and the private sector in the quality investment on conventional public transport services. Similarly, findings also show that the daily peak period is observed during the evening period across the highways with a slight variation in the counted traffic. The peak period was observed from $6 \mathrm{pm}-7 \mathrm{pm}$ on both Abeokuta-Lagos Highway and Sagamu-Benin Highway, at variance to Lagos-Ibadan Highway that reveals 5 pm-6 pm. Remarkably, a total traffic volume of 199,755 vehicles equivalent of 294,432 traffic volume in PCU) were recorded across the cordon points on the highways for a 36-hour week count.

Further investigation was conducted to reveal the statistical variation in the traffic volume observed on Tuesday, Thursday and Saturday on the selected highways. The result of the analysis of variance (ANOVA) through the F-ratio shows 980.598, 1205.827, and 1859.261 for Abeokuta-Lagos Highway, Sagamu- Benin Highway, and Lagos -Ibadan Highway respectively and the observed significant value revealed 0.000 for all the three highways, which is quite less than 0.05 confidence level while comparing the observed significant value with the significant value suggested in Table 2. Hence, we accept alternative hypothesis $\mathrm{H}_{1}$ and reject the null hypothesis $\mathrm{H}_{0}$., There is a statistically significant variation in traffic volume observed on Tuesday, Thursday and Saturday (p. value $\leq 0.05$ ). By implication, the variations in traffic volume for the observed days on Abeokuta -Lagos Highway, Sagamu- Benin Highway, and Lagos -Ibadan Highway were statistically significant, and as such the observed variations were not due to chance.

Table 1 Variation in traffic volume on the selected highways. Source: authors

\begin{tabular}{|c|c|c|c|c|c|c|}
\hline Highway & Source & $\begin{array}{c}\text { Type III Sum of } \\
\text { Squares } \\
\end{array}$ & Df & Mean Square & $F$ & Sig. \\
\hline Abeokuta - Lagos & $\begin{array}{l}\text { Between Groups } \\
\text { Within Groups }\end{array}$ & $\begin{array}{c}50402900.250 \\
565402.083\end{array}$ & $\begin{array}{c}1 \\
11\end{array}$ & $\begin{array}{c}50402900.250 \\
51400.189\end{array}$ & 980.598 & .000 \\
\hline Sagamu - Benin & $\begin{array}{c}\text { Between Groups } \\
\text { Within Groups }\end{array}$ & $\begin{array}{c}88846334.028 \\
810488.972 \\
\end{array}$ & $\begin{array}{c}1 \\
11 \\
\end{array}$ & $\begin{array}{c}88846334.028 \\
73680.816 \\
\end{array}$ & 1205.827 & .000 \\
\hline Lagos - Ibadan & $\begin{array}{c}\text { Between Groups } \\
\text { Within Groups }\end{array}$ & $\begin{array}{c}281272031.361 \\
1664097.639 \\
\end{array}$ & $\begin{array}{c}1 \\
11\end{array}$ & $\begin{array}{c}281272031.36 \\
151281.604 \\
\end{array}$ & 1859.261 & .000 \\
\hline
\end{tabular}




\subsection{Variation in the Traffic Flow Inbound and Outbound on the Highways}

The results of the observed variation in inbound and outbound traffic flows were presented in the summary of the daily traffic count by cordon points (Table 3). It is worth knowing that Lagos-Ibadan Highway out of the three sampled highways recorded the highest vehicular count for the observed days with a total of 100,627 vehicles, while Abeokuta - Lagos Highway observed the least vehicular count with a total of 42,597 vehicles. The highest average daily traffic count was observed on a Saturday for Lagos -Ibadan Highway with a sum of 3,405 vehicles per day, while Thursday recorded the highest average daily traffic count for Abeokuta -Lagos and Sagamu -Benin Highways with an average of 1,270 and 1,681 respectively. The outbound traffic flow was relative to the inbound traffic flow on both Lagos-Ibadan and Abeokuta-Lagos Highways, while Sagamu-Benin Highway has the inbound traffic relative to outbound traffic flow. The reason for this observed result is not unconnected to the fact that Lagos attracts more traffic than other Nigerian cities due to its socio-economic, political and geographical advantage.

Table 2 Summary of daily traffic count by cordon points. Source: authors

\begin{tabular}{lllllllllllll}
\hline & \multicolumn{3}{c}{ Abeokuta-Lagos } & \multicolumn{4}{c}{ Sagamu-Benin } & \multicolumn{4}{c}{ Lagos-Ibadan } \\
\hline Days & IN & OUT & $\begin{array}{l}\text { Daily } \\
\text { Total }\end{array}$ & $\begin{array}{l}\text { Ave/ } \\
\text { Day }\end{array}$ & IN & OUT & $\begin{array}{l}\text { Daily } \\
\text { Total }\end{array}$ & $\begin{array}{l}\text { Ave/ } \\
\text { Day }\end{array}$ & IN & OUT & $\begin{array}{l}\text { Daily } \\
\text { Total }\end{array}$ & $\begin{array}{l}\text { Ave/ } \\
\text { Day }\end{array}$ \\
\hline Tue & 5957 & 6313 & 12270 & 1023 & 8646 & 7919 & 16565 & 1380 & 13308 & 14053 & 27361 & 2280 \\
\hline Thu & 6656 & 8578 & 15234 & 1270 & 11336 & 8832 & 20168 & 1681 & 13460 & 18948 & 32408 & 2701 \\
\hline Sat & 7822 & 7271 & 15093 & 1258 & 9634 & 10188 & 19822 & 1652 & 17489 & 23369 & 40858 & 3405 \\
\hline Total & 20435 & 22162 & 42597 & & 29616 & 26939 & 56555 & & 44257 & 56370 & 100627 & \\
\hline
\end{tabular}

In the bid to understand the variation in traffic flow in and out, further investigation was conducted through Student " $t$ " test to determine the statistical variation between Inbound and Outbound traffic flows across the selected highways. The result of the Student' $t$ ' test shows through the calculated that significant values were 0.449, 0.569, 0.631 for Tuesday, Thursday and Saturday respectively (Table 4).

These observed significant values are greater than the table significant value (0.05). While comparing the calculated observed significant values for Tuesday (0.449), Thursday (0.569) and Saturday (0.631) with 0.05 level of significance, it can be deduced that the calculated significant values for the three days are greater than the tabulated value at 5\% level of significance. Hence, the null hypothesis $\left(\mathrm{H}_{0}\right)$ is accepted while the alternative hypothesis $\left(\mathrm{H}_{1}\right)$ is rejected. Therefore, there is no statistically significant difference between Inbound and Outbound traffic flow for each day Tuesday, Thursday and Saturday across the sampled highways. 
Table 3 Student' $t$ ' test result of the significant difference between traffic flow in and out.

Source: authors

\begin{tabular}{|c|c|c|c|c|c|c|c|c|}
\hline & \multicolumn{5}{|c|}{ Paired Differences } & $t^{*}$ & Df & Sig. (2-tailed) \\
\hline & \multirow[t]{2}{*}{ Mean } & \multirow{2}{*}{$\begin{array}{c}\text { Std. } \\
\text { Deviation }\end{array}$} & \multirow{2}{*}{$\begin{array}{l}\text { Std. Error } \\
\text { Mean }\end{array}$} & \multicolumn{2}{|c|}{$\begin{array}{l}95 \% \text { Confidence Interval of } \\
\text { the Difference }\end{array}$} & & & \\
\hline & & & & Lower & Upper & & & \\
\hline $\begin{array}{l}\text { TuesdayIN - } \\
\text { TuesdayOUT }\end{array}$ & 485.40000 & 1295.56216 & 579.39301 & -1123.25289 & 2094.05289 & 838 & 4 & 449 \\
\hline $\begin{array}{l}\text { ThursdayIN - } \\
\text { ThursdayOUT }\end{array}$ & 2303.40000 & 8307.28167 & 3715.12931 & -8011.45258 & 12618.25258 & 620 & 4 & 569 \\
\hline $\begin{array}{l}\text { ThursdayIN - } \\
\text { ThursdayOUT }\end{array}$ & 1883.60000 & 8112.62253 & 3628.07509 & -8189.55133 & 11956.75133 & 519 & 4 & 631 \\
\hline
\end{tabular}

*'t $\mathrm{t}$ ' is Significant at 5\%; (Calculate value: $\mathrm{t}=0.838$; Sig. value 0.449 (Tue), $\mathrm{t}=0.620$; Sig. value $=0.569(\mathrm{Thu})$ and $\mathrm{t}=0.519$; Sign. Value $=0.631$ (Sat)

\subsection{Physical Condition of the Selected Highways}

There are obvious variations in the factor that determine the quality of the physical condition of the highways in Nigeria. The quality of these factors is no doubt responsible for the traffic transit problems along the selected highways and thus resulting in unpredictable travel pattern, travel time and travel cost. For instance, results presented in Table 5 shows that most of the factors responsible for the quality of physical condition of the highways are mostly in the poor state along Abeokuta- Lagos and SagamuBenin Highways and at variance to Lagos-Ibadan Highway where most of the observed factors are in fair state. This is so because assiduous attention is paid to Lagos-Ibadan Highway unlike to others due to the associated level of importance of the highway at issue. As a result, there is a need for priority attention to the quality of these factors for efficient traffic planning and management on Nigerian highways.

Table 4 Quality of the physical condition of selected highways. Source: authors

\begin{tabular}{cccccccccc}
\hline Highway & Lighting & $\begin{array}{c}\text { Surface } \\
\text { Roughness }\end{array}$ & $\begin{array}{c}\text { Pavement } \\
\text { colour }\end{array}$ & $\begin{array}{c}\text { Night } \\
\text { visibility }\end{array}$ & $\begin{array}{c}\text { Road } \\
\text { geometric }\end{array}$ & $\begin{array}{c}\text { Traffic } \\
\text { control } \\
\text { devices }\end{array}$ & $\begin{array}{c}\text { Traffic } \\
\text { policing/ } \\
\text { management }\end{array}$ & $\begin{array}{c}\text { Emergency } \\
\text { response } \\
\text { team }\end{array}$ & $\begin{array}{c}\text { Traffic } \\
\text { signs/signals }\end{array}$ \\
\hline $\begin{array}{c}\text { Abeokuta } \\
- \text { Lagos }\end{array}$ & Poor & Poor & Fair & Poor & Fair & Poor & Poor & Poor & Poor \\
\hline $\begin{array}{c}\text { Sagamu } \\
- \text { Benin }\end{array}$ & Poor & Poor & Fair & Poor & Fair & Poor & Poor & Poor & Poor \\
\hline $\begin{array}{c}\text { Lagos } \\
- \text { Ibadan }\end{array}$ & Poor & Fair & Good & Poor & Good & Poor & Fair & Fair & Fair \\
\hline
\end{tabular}

\section{Conclusion and Recommendations}

The study has explored the importance and the need for a redressing traffic volume survey on major highways in Nigeria with a special focuson three prominent highways in Ogun State (Lagos-Ibadan, Sagamu-Benin and Abeokuta-Lagos) that are more or less vital links for the national and regional 
accessibility and connectivity. Interestingly, the study through its major findings revealed that Car/SUV traffic accounted for the most voluminous vehicular traffic on the selected highways. This indicates that Car/SUV vehicle type is perhaps the most dominant traffic on Nigeria roads resulting from the failing government and private sector investment in the conventional public transport system in conjunction with a weak policy and poor intermodal system. Also, this study revealed no statistically significant variation in the inbound and outbound traffic flow, and thus confirms that the observed variation results from a poor physical condition along the road corridors as well as rush-to-avoid-longer travel time and unnecessary cost along traffic routes. The nature of the road transport planning and highway maintenance in Nigeria have remained major challenges that have encouraged never-ending quagmires of the road transport and traffic across the country due to the obvious neglect of a traffic volume survey and the total decline in the provision and maintenance of basic infrastructural facilities such as traffic management devices vis-à-vis control, monitoring and priority devices; road lightning; night visibility mechanism; road geometry and layout; road signs and signals etc. which this study noted as agents for a high-quality physical condition of road networks that confirmed causing clustered nature of traffic bottlenecks on Nigerian roads.

Based on these findings, the study recommends a total redress of traffic volume survey and road transport planning along road corridors; installation of automated traffic count devices including permanent count devices and videotaping devices along major traffic corridors; periodic maintenance of road networks with quality facilities, installation of modern (automated and manual) traffic management devices along road corridors; prompt road improvement and expansion with right geometry and layout as well as the establishment of quality traffic database. In addition, research units should be embraced for efficient, safe, and quality road transport system in Nigeria and countries with similar traffic issues.

\section{References}

[1] Oyesiku, O.K. (2002). From womb to tomb. 24th Inaugural Lecture, Olabisi Onabanjo University. Ago-Iwoye: Olabisi Onabanjo University.

[2] Badejo, B.A. (2011). Transportation removing the clogs to Nigeria's development. Lagos: Anchorage Press and Publishers.

[3] Salisu, U.O. (2019). State of transport administrative structure in Lagos, Ogun, and Oyo States, Nigeria. Journal of Spatial and Organizational Dynamics JSOD 7(1), 68-85.

[4] Ministry of Works and Transport (2004). Traffic data collection and analysis: Road department, Gaborone, Botswana. Botswana: MWT Publication. 
[5] Jain, K., Jain, S.S. \& Singh M. (2016). Traffic flow characteristics for multilane highways in India. Transport Research Procedia 17, 468-477.

[6] Sharma, S.C. (1994). Seasonal traffic counts for a precise estimation of AADT. ITE Journal 64(9), 43-41.

[7] European Commission JRC (2008). Road traffic data: Collection methods and applications. European Commission.

[8] Padshala, A. (2014). Traffic studies of urban mid-block section: A case study of Pragatinagar to Akhbarnagar and Akhbarnagar to Ranip crossroad. International Journal of Research in Engineering and Technology 3(6), 383-385.

[9] Udit, B. \& Mandar, V.S. (2013). Traffic surveying and analysis. International Journal of Application or Innovation in Engineering and Management. Special issue 1-8.

[10]Bruton, M.J. (1975). Introduction to transport planning. London: The Author Press.

[11]Banister, D. (2002). Transport Planning (2nd ed). London: Routledge.

[12]Bharadwaj, H., Sharma, S., Sharma, R. \& Kumar, V. (2016). Traffic volume study of Sitapura, Jaipur. SSRG International Journal of Civil Engineering 3(7), 111-114.

[13] Shanu, K., Dakshesh, K., Adnan K. \& Ahtesham A. (2016). Traffic volume studies and analysis. International Journal of Advanced Research in Engineering Technology and Sciences 2(3), 276278.

[14]Oni, S.I, Ege, E.E., Hammed, T. \& Afaye, B. (2011). An analysis of road traffic volume on Nigeria's Lagos-Ibadan Expressway. Journal of Logistics and Transport 4(1), 112-126.

[15]Traffic Volume Count 3 (n.d). Traffic volume count 3. Retrieved April 6, 2016, from http://www.ctre.iastate.edu/.../traffichandbook/ 